\title{
Cultivation Methods for Tomato (Lycopersicon esculentum Mill.) with High Soluble Solids Content Using the Vertically Split Root System
}

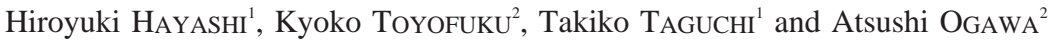 \\ ${ }^{1}$ Agricultural Experiment Station, Akita Prefectural Agriculture, Forestry and Fisheries Research Center, Akita 010-1231, Japan \\ ${ }^{2}$ Crop Science Laboratory, Department of Biological Production, Akita Prefectural University, \\ Shimosinjyou-nakano 241-438, Akita 010-0195, Japan
}

(Received December 11, 2013; Accepted April 8, 2014)

\begin{abstract}
For the cultivation of tomatoes with high soluble solids content, the root system was split vertically and irrigation to the upper part of the root system was stopped to create split vertically (SR treatment), while the irrigation amount per plant was maintained to the lower part at the same level as that of a non-stress treatment (Control). In Experiment 1, the soluble solids content in the SR treatment (1.3 Brix \%) was significantly higher than that of the Control. However, there were no differences in plant growth and fruit quality between the SR treatment and the treatment in which the amount of water supplied was half of that of the Control. These results indicated that tomatoes with high soluble solids content in the SR treatment were cultivated without reducing the irrigation amount compared to that of the Control. In Experiment 2, the difference in the volume of the root zone in the lower container in the SR treatment affected the fresh weight per fruit and soluble solids content when sand was used in the lower container. However, when Andosol was used in the lower container, the difference in the volume of the root zone did not affect the yield and soluble solids content of the tomatoes.
\end{abstract}

Keywords : deficit irrigation, leaf water potential, soluble solids content, tomato, vertically split root system

\section{INTRODUCTION}

The tomato (Lycopersicon esculentum Mill.) is among the most important vegetables in the world, and improving tomato quality is a key issue for growers (Ho, 1999; Dorais et al., 2001). Sweetness is one important factor that contributes to tomato quality and is determined by the amount of soluble solids in the fruit (Johnstone et al., 2005). There are some reports suggesting that the cultivation of tomatoes with high sugar content can be achieved by the application of drought stress and salt stress.

Commonly, water-saving methods that induce drought stress, such as deficit irrigation (DI), are used. In DI, the amount of irrigation to the whole root zone is restricted to less than the amount lost by evapotranspiration. However, it has been reported that DI cultivation not only decreases leaf water potential (Pulupol et al., 1996) and increases soluble solids content but also decreases yield (Mitchell et al., 1991; Pulupol et al., 1996; Johnstone et al., 2005). Furthermore, sugar (including hexose, glucose, and fructose) and ion (potassium, magnesium, and calcium) contents increase under DI cultivation (Mitchell et al., 1991; Pulupol et al., 1996).

Salt stress conditions are typically achieved by adjusting the concentration of the nutrient solution to modify water availability and enhance soluble solids content (Dorais et al., 2001). Under high electrical conductivity (EC) conditions, plant growth is affected by drought due to the low water potential of the nutrient solution (Dorais et al., 2001). High EC conditions induce a decrease in water availability and uptake, and thus reduce xylem transport of water. As a result, drought stress occurs in the shoots and fruits and the soluble solids content increases (Gao et al., 1998; Dorais et al., 2001; Martinez et al., 2012). On the other hand, studies have shown that yields decrease under salt stress conditions (Ieperen, 1996; Cuartero and Fernández-Muñoz, 1998; Bolarin et al., 2001; Martinez et al., 2012).

There are some problems for growers of tomatoes with high soluble solids content when irrigation is restricted or salt stress is treated. First, irrigation control is difficult. In DI cultivation, the amount of irrigation to the plant is strictly controlled. The minimum amount of water required to maintain plant growth must be applied. Therefore, a soil moisture sensor is needed to ensure strict water control. Furthermore, it is difficult to cultivate tomatoes with high soluble solids stability. Second, when tomatoes with high soluble solids content are cultivated by the application of salt stress, the soil in which they are cultivated has to be replaced after a certain period because salt accumulation causes salt injury. Third, when tomatoes with high soluble solids content are cultivated hydroponically, it is necessary to strictly control the components of the nutrient solutions. In light of these problems, it is difficult for the grower to cultivate tomatoes with high soluble solids content; even so, there is still a proportion of growers who strictly control water and nutrient conditions in order to produce tomatoes

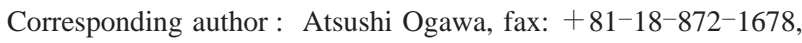
e-mail : 111111@akita-pu.ac.jp 
with a high soluble solids content.

To solve these problems and enable the growth of tomatoes with high soluble solids content, we investigated a cultivation method in which we did not reduce irrigation nor increase EC in the nutrient solution. We assumed that tomatoes with high soluble solids content could be cultivated by drought stress treatment on part of the root system without reducing the amount of irrigation. In this study, we split a tomato root system vertically, and the amount of water supplied to the lower part of the root system was equal to that of non-stress cultivation, although the irrigation to the upper part of the root system was stopped to apply drought stress. Additionally, we investigated the relationship among irrigated root zone, water relations of shoots, and fruit quality. In Experiment 1, the split-root method was compared with the DI method. In Experiment 2 , the effects of the volume of root zones and types of soil in the upper and lower containers in the split-root method on the water relations and fruit quality were investigated.

\section{MATERIALS AND METHODS}

\section{Growing plants}

Middy tomato (Lycopersion esculentum L. cv. 'Louis 60 ' grafted onto 'Vespa' rootstock) seedlings were used for the two experiments. Plants were grown in a greenhouse located at the Agricultural Experiment Station, Akita Prefectural Agriculture, Forestry and Fisheries Research Center, Akita, Japan.

Experiment 1

Seeds were sown in propagation medium on January 4, 2007. After 62 days, seedlings were transplanted to the containers described below (Fig. 1):

(1) Vertically split root system (SR treatment): the upper container $(50 \mathrm{~L}$ volume, $50 \times 50 \times 20 \mathrm{~cm}$ ) with a hole ( $8 \mathrm{~cm}$ diameter) in the center of the base was connected vertically to the lower container $(12.5 \mathrm{~L}$ volume, $25 \times 25$ $\times 20 \mathrm{~cm})$ by a polyvinyl chloride tube $(10 \mathrm{~cm}$ length, $8 \mathrm{~cm}$ diameter). Black soil (Andosol) $(37.5 \mathrm{~L})$ was added to the upper container and sandy soil $(9.4 \mathrm{~L})$ was added to the
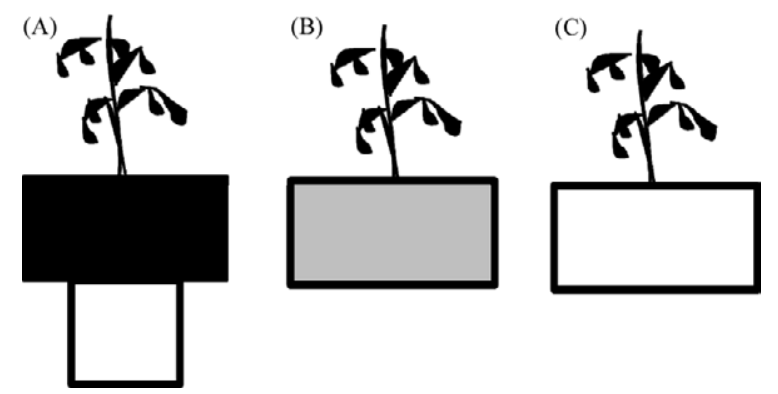

Fig. 1 Experimental design of (A) split root (SR) system treatment, (B) deficit irrigation (DI) treatment, and (C) irrigation treatment (Control). In the SR treatment, the same amount of water as used in the control treatment was supplied to the lower container $(1500 \mathrm{~mL}$ per day, white square), although irrigation to the upper container (black square) was stopped. In the DI treatment, half the amount of water used in the control treatment was supplied (750 mL per day, gray square). lower container.

(2) Deficit irrigation (DI treatment): Andosol (37.5 L) was added to the 50 - $\mathrm{L}$ container $(50 \times 50 \times 20 \mathrm{~cm})$.

(3) Irrigation (Control): Containers and amounts of soil were the same as those used in the DI treatment.

One line of drip tube (Stream Line; Netafim Corp., Fresno, California, USA) was located above each container. All containers were irrigated in all treatments for 32 days after transplantation, as appropriate. Thereafter, in SR treatment, irrigation to the upper container was stopped and $1500 \mathrm{~mL}$ of water per day was supplied only to the lower container. In DI treatment, irrigation was limited to 750 $\mathrm{mL}$ per day. In the Control, $1500 \mathrm{~mL}$ of water per day was supplied.

All lateral shoots were removed. The main shoot of each plant was pinched to leave two leaves above the 5th truss. Combined and controlled fertilizer containing $15 \mathrm{~g}$ nitrogen per plant was added to the upper container in the SR treatment and to the container in the DI treatment and Control.

One plant was planted in each container. Four replicates of each treatment were used and the means of each measured item were calculated.

Experiment 2

Seeds were sown in the propagation medium on July 13, 2007. After 49 days, seedlings were transplanted to an upper container $(50 \mathrm{~L}$ volume, $50 \times 50 \times 20 \mathrm{~cm}$ ) with a hole $(8 \mathrm{~cm}$ diameter) in the center of the base that was connected vertically to a lower container $(50 \mathrm{~L}$ volume, $50 \times$ $50 \times 20 \mathrm{~cm}$ or $12.5 \mathrm{~L}$ volume, $25 \times 25 \times 20 \mathrm{~cm}$ ) by a polyvinyl chloride tube $(10 \mathrm{~cm}$ length, $8 \mathrm{~cm}$ diameter $)$. Five treatments were established as described below:

(1) Andosol 1/2: $9.4 \mathrm{~L}$ Andosol was added to the lower container $(12.5 \mathrm{~L})$ and drought stress was applied to the upper container.

(2) Andosol 1: $37.5 \mathrm{~L}$ Andosol was added to the lower container $(50 \mathrm{~L})$ and drought stress was applied to the upper container.

(3) Sand 1/2: 9.4 L sandy soil was added to the lower container $(12.5 \mathrm{~L})$ and drought stress was applied to the upper container.

(4) Sand 1: 37.5 L sandy soil was added to the lower container $(50 \mathrm{~L})$ and drought stress was applied to the upper container.

(5) Control: $37.5 \mathrm{~L}$ Andosol was added to the lower container $(50 \mathrm{~L})$, and the upper and lower containers were irrigated constantly.

In all treatments, $37.5 \mathrm{~L}$ Andosol was added to the upper container.

Two lines of drip tube were located above each container. The upper container was irrigated in all treatments after transplantation, as appropriate. For 24 days after the 14th day of transplantation, the upper and lower containers were irrigated with $1500 \mathrm{~mL}$ of water per day. Thereafter, irrigation to the upper containers was stopped for drought stress treatments. In the Control, irrigation to both containers was continued.

All lateral shoots were removed. The main shoot of each plant was pinched to leave two leaves above the 5th 
truss. Combined and controlled fertilizer containing $15 \mathrm{~g}$ nitrogen per plant was added to the upper container.

One plant was planted in each container. Three plants were used for each treatment and the means of each measured item were calculated.

\section{Measurement}

Leaf water potential was measured at the leaflet located directly above the 4th truss in Experiment 1 and the 3rd truss in Experiment 2 at 11:00 using a pressure chamber (Model 600; PMS Instrument Company, Oregon, USA). In Experiment 2, the rates of photosynthesis and stomatal conductance were measured at the leaflet located directly above the 3rd truss from 11:00 to $14: 00$ by a portable photosynthesis system (LI-6400; Li-Cor Inc., Lincoln, NE, USA). At the time of each measurement, artificial illumination was supplied to the leaf from a red-blue lightemitting diode (LED) light source, and ambient $\mathrm{CO}_{2}$ partial pressure was supplied by a LI-6400 $\mathrm{CO}_{2}$ mixer. Photosynthetic photon flux density (PPFD) and $\mathrm{CO}_{2}$ concentration in the chamber were set to $2000 \mu \mathrm{mol} \mathrm{m} \mathrm{m}^{-2} \mathrm{~s}^{-1}$ and $500 \mathrm{ppm}$, respectively.

Fruits were harvested from April 27 to June 25, 2007 in Experiment 1, and from October 11 to December 28, 2007 in Experiment 2. All fruits were harvested, the fresh weight of each fruit was measured, juice was squeezed from all parts of the tomato, and soluble solids content (Brix \%) was also measured using a refractometer (Palette PR-100 Digital Refractometer; Atago Co., Ltd., Tokyo, Japan). In Experiment 1, leaf stems and roots were sampled. Leaf area of all parts of the plant at the end of the harvest was measured with an area meter (Li-3100; Li-Cor Inc., Lincoln, Nebraska, USA). Next, leaves and stems were dried for 7 days at $80^{\circ} \mathrm{C}$, and dry weights were measured. Roots were collected from each container, washed carefully, fixed in FAA (5\% formaldehyde: $50 \%$ ethanol: $5 \%$ acetic acid, v/v/v), and kept for 2 days. Root lengths were measured with a Comair Root Length Scanner (Commonwealth Aircraft Corporation Ltd., Port Melbourne, Australia). Changes in soil water content were measured with a time domain reflectometry (TDR) probe (model EC-5; Decagon Devices Inc., Pullman, WA, USA). The TDR probe was installed $10 \mathrm{~cm}$ from the base of plant.

\section{RESULTS}

\section{Experiment 1}

Drought in the SR and DI treatments affected fresh weight, fruit yield per plant, and soluble solids content, although there were no differences in the number of fruit per plant among the three treatments (Table 1). The fresh weights per fruit in the SR and DI treatments were $22.2 \mathrm{~g}$ and $23.4 \mathrm{~g}$, respectively. These weights represent only $57 \%$ and $60 \%$ of that of the Control (39.1 g). As a result, the fruit yields per plant in the SR and DI treatments were $47 \%(745 \mathrm{~g})$ and $54 \%(858 \mathrm{~g})$ that of the Control (1,589 g), respectively. Soluble solids content (Brix \%) in the SR and DI treatments was $1.3 \%$ and $1.5 \%$ higher than in the Control, respectively. Soluble solids contents exceeded $10 \%$ in the 4th and 5th trusses of the SR treatment and from the 3rd to the 5th truss of the DI treatment (data not shown). There were no significant differences in fresh weight and soluble solids content in tomatoes harvested from all trusses between the SR and DI treatments.

Drought in the SR and DI treatments decreased leaf water potential (Fig. 2). In the SR treatment, leaf water potential began to decrease soon after irrigation was stopped and declined from $-0.8 \mathrm{MPa}$ to $-1.7 \mathrm{MPa}$ over the next 6 days. In the DI treatment, leaf water potential began to decrease 6 days after irrigation was stopped and declined from $-0.8 \mathrm{MPa}$ to $-1.3 \mathrm{MPa}$ over the next 3 days. Afterwards, water potentials stabilized at approximately $-1.6 \mathrm{MPa}$ and $-1.3 \mathrm{MPa}$ in SR and DI treatments, respectively. In the Control, leaf water potential was maintained between $-0.7 \mathrm{MPa}$ and $-0.8 \mathrm{MPa}$ during the experimental period.

Drought in the SR and DI treatments also affected plant growth (Table 2). In the SR treatment, the shoot wilted as DI treatment. Dry weights of the roots in the SR

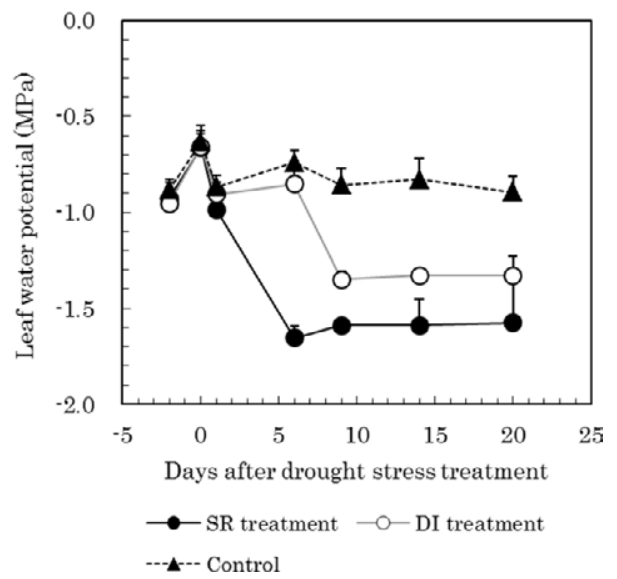

Fig. 2 Changes in water potential in the leaflet located directly above the 3 rd truss as affected by split root system (SR) and deficit irrigation (DI) treatment after drought stress treatment. Each value shows the mean \pm standard error $(n=4)$.

Table 1 Changes in fruit yield and soluble solids content at harvest as affected by split root system (SR) and deficit irrigation (DI) treatment.

\begin{tabular}{ccccc}
\hline Treatment & $\begin{array}{c}\text { Average of fresh } \\
\text { weight per fruit }(\mathrm{g})\end{array}$ & $\begin{array}{c}\text { Number of fruits } \\
\text { per plant }\end{array}$ & $\begin{array}{c}\text { Fruit yield per } \\
\text { plant }(\mathrm{g})\end{array}$ & $\begin{array}{c}\text { Average of soluble solids } \\
\text { content (Brix \%) }\end{array}$ \\
\hline SR & $22.2 \mathrm{~b}$ & $33.5 \mathrm{a}$ & $745 \mathrm{~b}$ & $9.4 \mathrm{~b}$ \\
DI & $23.4 \mathrm{~b}$ & $36.8 \mathrm{a}$ & $858 \mathrm{~b}$ & $9.6 \mathrm{~b}$ \\
\hline Control & $39.1 \mathrm{a}$ & $40.8 \mathrm{a}$ & $1589 \mathrm{a}$ & $8.1 \mathrm{a}$
\end{tabular}

Each value shows the mean $(n=4)$. In each column, means followed by the same letter are not significantly different according to Tukey's multiple comparison test $(P<0.05)$. 
H. HAYASHI ET AL.

Table 2 Changes in root and shoot growth as affected by split root system (SR) and deficit irrigation (DI) treatment.

\begin{tabular}{|c|c|c|c|c|c|c|}
\hline Treatment & Root dry weight (g) & Root length (m) & $\begin{array}{l}\text { Specific root length } \\
(\mathrm{m} / \mathrm{g})\end{array}$ & Stem dry weight $(\mathrm{g})$ & Leaf dry weight (g) & Leaf area $\left(\mathrm{m}^{2}\right)$ \\
\hline SR & $29.6(1.2) \mathrm{c}$ & $3238(203) \mathrm{b}$ & $110.0(163) \mathrm{a}$ & $79.6 \mathrm{c}$ & $40.1 \mathrm{c}$ & $1.00 \mathrm{~b}$ \\
\hline DI & $53.4 \quad$ b & $8007 \quad a$ & $150.0 \quad \mathrm{~b}$ & $112.6 \mathrm{~b}$ & $62.9 \mathrm{~b}$ & $1.21 \mathrm{~b}$ \\
\hline Control & 87.0 & 9547 & 110.0 & $176.1 \mathrm{a}$ & $109.0 \mathrm{a}$ & $1.85 \mathrm{a}$ \\
\hline
\end{tabular}

Each value shows the mean $(\mathrm{n}=4)$. In each column, means followed by the same letter are not significantly different according to Tukey's multiple comparison test $(P<0.05)$. The values for the lower container are shown in parentheses.

Table 3 Changes in fruit yield, soluble solids content, and ratio of blossom-end rot fruit at harvest as affected by the type of soil and volume of the root zone.

\begin{tabular}{cccccc}
\hline Treatment & $\begin{array}{c}\text { Average of fresh } \\
\text { weight per fruit }(\mathrm{g})\end{array}$ & $\begin{array}{c}\text { Number of fruits } \\
\text { per plant }\end{array}$ & $\begin{array}{c}\text { Fruit yield per plant } \\
(\mathrm{g})\end{array}$ & $\begin{array}{c}\text { Average of soluble sol- } \\
\text { ids content (Brix \%) }\end{array}$ & $\begin{array}{c}\text { Ratio of blossom- end } \\
\text { rot fruit }(\%)\end{array}$ \\
\hline Andosol 1/2 & $40.3 \mathrm{~b}$ & $38.3 \mathrm{a}$ & $1640 \mathrm{~b}$ & $7.3 \mathrm{~b}$ & $5.6 \mathrm{ab}$ \\
Andosol 1 & $43.2 \mathrm{~b}$ & $41.0 \mathrm{a}$ & $1779 \mathrm{ab}$ & $7.0 \mathrm{~b}$ & $5.8 \mathrm{ab}$ \\
\hline Sand $1 / 2$ & $40.6 \mathrm{~b}$ & $38.0 \mathrm{a}$ & $1577 \mathrm{~b}$ & $7.2 \mathrm{~b}$ & $12.1 \mathrm{~b}$ \\
Sand 1 & $32.1 \mathrm{c}$ & $35.3 \mathrm{a}$ & $1152 \mathrm{~b}$ & $8.3 \mathrm{c}$ & $4.1 \mathrm{a}$ \\
\hline Control & $59.1 \mathrm{a}$ & $42.3 \mathrm{a}$ & $2555 \mathrm{a}$ & $6.1 \mathrm{a}$ & $0.7 \mathrm{a}$ \\
\hline
\end{tabular}

Each value shows the mean $(n=3)$. In each column, means followed by the same letter are not significantly different according to Tukey's multiple comparison test $(P<0.05)$.

and DI treatments were $34 \%$ and $61 \%$ of those in the Control, respectively; a difference that was significantly lower. Root lengths in the SR treatment were $34 \%$ of those in the Control, which was also significantly lower. However, the root lengths in the DI treatment were $83 \%$ of those in the Control and were not significantly different. In addition, the specific root length in the SR treatment was the same as that of the Control, although the specific root length in the DI treatment was significantly higher than that of the Control. In the SR treatment, the dry weights of the roots and root lengths in the lower containers were $4 \%$ and $6 \%$ of the totals, respectively, and the specific root length in the lower containers was significantly higher than that of the Control. For the shoots, dry weights of the stems and leaves and leaf area in the SR and DI treatments were significantly lower than those of the Control.

\section{Experiment 2}

Drought stress treatments affected fruit yield, soluble solids content, and the ratio of blossom-end rot fruit, but did not affect the number of fruit per plant (Table 3). There were no significant differences among the Andosol 1, Andosol 1/2, and Sand 1/2 treatments. The Sand 1 treatment was lower in the fresh weight per fruit and was higher in soluble solids content than those of the other three stress treatments. The fresh weight per fruit in the drought stress treatments ranged from 54\% (Sand 1 treatment) to $73 \%$ (Andosol 1 treatment) lower than that of the Control. The fruit yield per plant in the drought stress treatments ranged from $45 \%$ (Sand 1 treatment) to $70 \%$ (Andosol 1 treatment) lower than that of the Control. Soluble solids content in the drought stress treatments ranged from $0.9 \%$ (Andosol 1 treatment) to $2.2 \%$ (Sand 1 treatment) higher than that of the Control. Ratios of blossom-end rot fruit in all drought stress treatments were higher than that of the Control $(0.7 \%)$.

Drought stress treatments in the upper container immediately decreased leaf water potential (Fig. 3). In the Sand 1 treatment, leaf water potential declined from -0.9

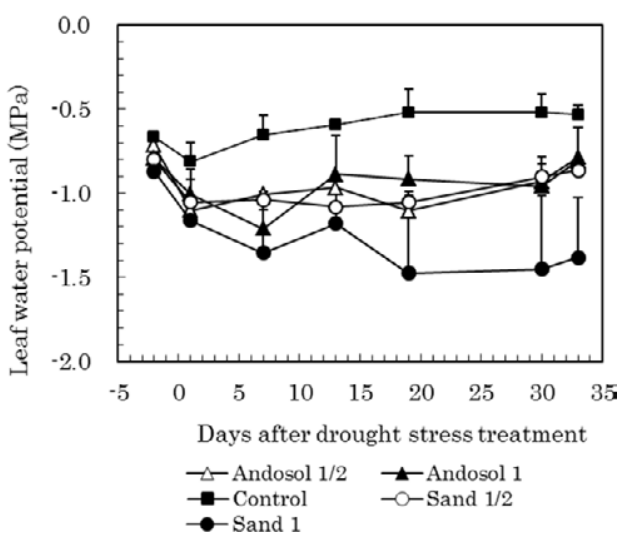

Fig. 3 Changes in water potential in the leaflet located directly above the 3rd trust in split root system after drought stress treatment. Each value shows the mean \pm standard error $(n=3)$.

MPa to $-1.5 \mathrm{MPa}$ for 19 days after irrigation was stopped and strict drought stress was applied. In the other three stress treatments, leaf water potential declined for 4 or 10 days and then water potential was maintained at approximately $-1.0 \mathrm{MPa}$. In the Control, leaf water potential was maintained between -0.7 and $-0.5 \mathrm{MPa}$.

Differences in soil type and root zone volume during the 19 days after the drought stress treatments did not cause any significant differences in the rates of photosynthesis and stomatal conductance (Tables 4 and 5). Drought stress treatments in the upper container decreased the rates of photosynthesis and stomatal conductance compared to the Control. Stomatal conductance in the drought stress treatments after 1 day of treatment was significantly lower than that in the Control. After 19 days, the stomatal conductance of the drought stress treatments was $10 \%$ (Sand 1 treatment) to $47 \%$ (Andosol 1 treatment) of that of the Control. The rates of photosynthesis in the drought stress treatments after 1 day of treatment were also significantly lower than those of the Control. After 19 days, the rates of 
HIGH SOLUBLE SOLIDS CONTENT IN TOMATO

Table 4 Changes in stomatal conductance $\left(\mathrm{mol} \mathrm{m}^{-2} \mathrm{~s}^{-1}\right)$ at harvest as affected by the type of soil and volume of the root zone.

\begin{tabular}{ccccc}
\hline \multirow{2}{*}{ Treatment } & \multirow{2}{*}{$\begin{array}{c}\text { 1 day before } \\
\text { stress treatments }\end{array}$} & \multicolumn{3}{c}{ Days after stress treatments } \\
\cline { 3 - 5 } & $0.54 \mathrm{~b}$ & $0.13 \mathrm{~b}$ & $0.14 \mathrm{~b}$ & $0.05 \mathrm{~b}$ \\
Andosol 1/2 & $0.44 \mathrm{ab}$ & $0.04 \mathrm{~b}$ & $0.06 \mathrm{~b}$ & $0.14 \mathrm{ab}$ \\
Andosol 1 & $0.50 \mathrm{~b}$ & $0.05 \mathrm{~b}$ & $0.09 \mathrm{~b}$ & $0.07 \mathrm{~b}$ \\
\hline Sand 1/2 & $0.25 \mathrm{a}$ & $0.03 \mathrm{~b}$ & $0.03 \mathrm{~b}$ & $0.03 \mathrm{~b}$ \\
Sand 1 & $0.51 \mathrm{~b}$ & $0.57 \mathrm{a}$ & $0.55 \mathrm{a}$ & $0.30 \mathrm{a}$ \\
\hline Control & &
\end{tabular}

Each value shows the mean $(n=3)$. In each column, means followed by the same letter are not significantly different according to Tukey's multiple comparison test $(P<0.05)$.

Table 5 Changes in photosynthetic rate $\left(\mu \mathrm{mol} \mathrm{m} \mathrm{m}^{-2} \mathrm{~s}^{-1}\right)$ at harvest as affected by the type of soil and volume of the root zone.

\begin{tabular}{ccrcr}
\hline \multirow{2}{*}{ Treatment } & 1 day before stress & \multicolumn{3}{c}{ Days after stress treatments } \\
\cline { 3 - 5 } & treatments & 1 day & 7 days & 19 days \\
\hline Andosol $1 / 2$ & $27.6 \mathrm{~b}$ & $14.9 \mathrm{~b}$ & $16.1 \mathrm{ab}$ & $9.6 \mathrm{ab}$ \\
Andosol 1 & $24.8 \mathrm{ab}$ & $8.2 \mathrm{~b}$ & $9.3 \mathrm{~b}$ & $14.6 \mathrm{ab}$ \\
\hline Sand $1 / 2$ & $26.7 \mathrm{ab}$ & $9.6 \mathrm{~b}$ & $11.7 \mathrm{~b}$ & $11.0 \mathrm{ab}$ \\
Sand 1 & $22.9 \mathrm{a}$ & $6.2 \mathrm{~b}$ & $5.1 \mathrm{~b}$ & $5.0 \mathrm{~b}$ \\
\hline Control & $27.6 \mathrm{~b}$ & $27.1 \mathrm{a}$ & $25.3 \mathrm{a}$ & $20.3 \mathrm{a}$ \\
\hline
\end{tabular}

Each value shows the mean $(n=3)$. In each column, means followed by the same letter are not significantly different according to Tukey's multiple comparison test $(P<0.05)$.

photosynthesis in the drought stress treatments were 25\% (Sand 1 treatment) to $72 \%$ (Andosol 1 treatment) of that of the Control.

The relationship among leaf water potential, fresh weight per fruit, and soluble solids content at harvest were found to determine the adequate degree of drought stress needed to increase soluble solids content and to maintain a high yield. There was a significant positive correlation between leaf water potential and fresh weight per fruit $(\mathrm{R}=0.875$, Fig. $4 \mathrm{~A})$, and there were significant negative correlations between soluble solids content and leaf water potential $(\mathrm{R}=0.807$, Fig. $4 \mathrm{~B})$ and fresh weight per fruit and soluble solids content $(\mathrm{R}=0.903$, Fig. $4 \mathrm{C})$.

Figure 5 shows the change in soil, water content in the upper container of the Andosol 1/2 treatment from the 4th day to the 6th day after the drought stress treatment. The soil water content gradually decreased during the 3 days. Diurnal changes were evident in this value. Each day, the water content rose at approximately 10:00 and declined at approximately 17:00. A similar phenomenon was also ob- served in other split root treatments.

\section{DISCUSSION}

In Experiment 1, soluble solids content in the SR treatment was significantly higher than in the Control (Table 1). There were no differences in plant growth and fruit quality between the SR and DI treatments (Table 1). These results showed that tomatoes with high soluble solids content were cultivated in the vertically split root system (SR treatment) even though water was supplied in the same amount as in the Control. Previous studies have reported that DI cultivation increases soluble solids content (Mitchell et al., 1991; Pulupol et al., 1996; Johnstone et al., 2005) and decreases leaf water potential (Pulupol et al., 1996; Tahi et al., 2007; Savić et al., 2009), stomatal conductance (Tahi et al., 2007; Savić et al., 2009), and yield (Pulupol et al., 1996; Kirda et al., 2004; Sirigu et al., 2006; Savić et al., 2008). These results agree with our findings for the SR treatment. In addition, the increase in specific root length in SR and DI
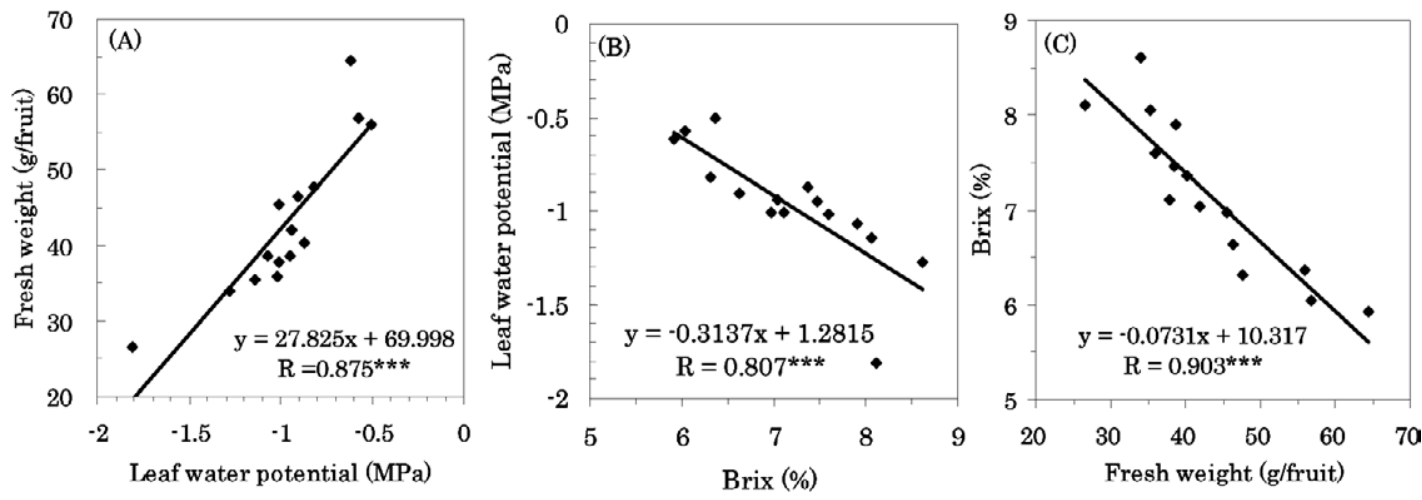

Fig. 4 Relationship (A) between the average of leaf water potential and fresh weight, (B) between the average of soluble solids content (Brix \%) and leaf water potential, and (C) between the average of fresh weight and soluble solids content at harvest in Experiment 2. *** indicates that there is a significant correlation at the $0.1 \%$ level. 
treatments (Table 2) suggests an increase in the lateral roots (Ostonen et al., 2007). Specific root length has been reported to be increased by drought stress (Azhiri-Sigari et al., 2000; Bañoc et al., 2000). Therefore, we applied drought stress to the shoots in the SR treatment, as is commonly done in DI treatment, although sufficient water was supplied to the lower part of the root system in the SR treatment, as is commonly the case in the Control.

In Experiment 2, the change in fresh weight per fruit and soluble solids content was greater in the Sand 1 treatment than in the other three stress treatments (Table 3). This result suggested that the volume of the lower container did not affect to the fruit yield and quality when soil with a high water retention ability, like Andosol, was used in the lower container. However, the larger volume of the lower container affected the yield and quality when soil with a low water retention ability, like sand, was used in the lower container.

An adequate degree of drought stress is required to increase soluble solids content and to maintain high yield. The intersection points of the three approximation formulas in Fig. 3 were $-0.97 \mathrm{MPa}, 43.1 \mathrm{~g}$, and $7.2 \%$ in leaf water potential, fresh weight per fruit, and soluble solids contents, respectively. In the Sand 1 treatment, excessive stress was applied. On the other hand, in the other three stress treatments, there were no differences between the calculated values and the measured values; therefore, we concluded that an adequate degree of drought stress was applied in these treatments. In the present study, the SR treatment increased soluble solids content to a similar degree as did DI treatment, although the same amount of water was supplied as in the Control. Three factors were considered in compiling the observed results. First, when the same amount of water was supplied to the lower container of SR treatment as the Control, the root system could not absorb the supplied water, because the root volume of lower container was smaller than that of the Control (Table 2). As the result, sufficient water was not transferred to the shoot. Second, the abscisic acid (ABA) was transferred from the dried upper part of the root to the shoots in the SR treatment. The stress signals mediated by ABA were transferred from the root to the shoot in drought stress conditions (Davies and Zhang, 1991; Bano et al., 1993; $\mathrm{Zhu}, 2002)$. Increased ABA concentration induced an increase in soluble solids content in the tomatoes (Savić et al., 2009). Third, the water absorbed from the lower part of the root was released to the dried upper part by hydraulic lift (Caldwell et al., 1998; Liste and White, 2008; Burgess, 2010; Sekiya et al., 2010). Soil water content in the dried upper part increased slightly at midday (Fig. 5). However, it was not clarified how much water was released by the hydraulic lift to the upper dried part and how it contributed to the stress to the shoot. Further studies are necessary to clarify about these points. By these factors, it was considered that sufficient and optimal drought stress was applied to the shoots to increase the soluble solids content of the tomatoes by drying the upper part of the root zone.

In this study, the cultivation method needed to produce tomatoes with high soluble solids content was

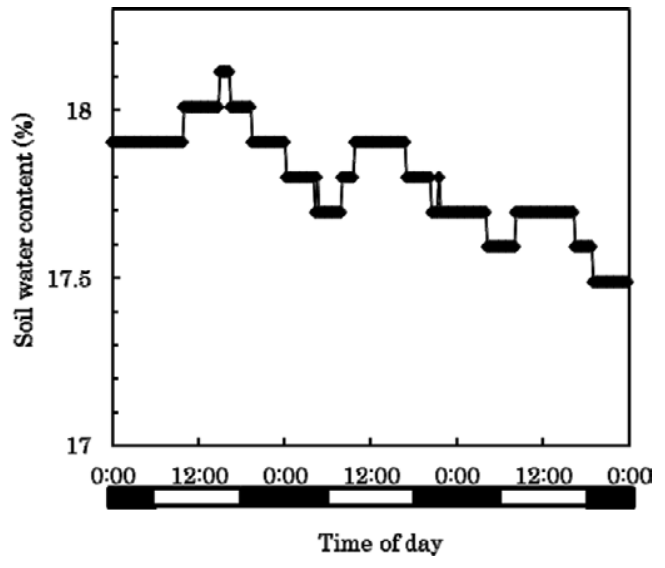

Fig. 5 Changes in soil water content in the upper layer of the Andosol 1/2 treatment from the 4th day to the 6th day after drought stress treatment. Black bar indicates night time and white bar indicates day time.

illustrated. This was achieved when the root system of the tomato plants was split vertically and drought stress was applied by stopping irrigation to the upper part of the root system while maintaining constant irrigation to the lower part of the root system. Thus, tomatoes with high soluble solids content, which was the same quality brought about by drought treatment (DI treatment), can be cultivated with no change in the amount of irrigation and EC in the nutrient solution. On the other hand, there are some problems that remain with this method. The fresh weight per fruit decreased with DI treatment (Table 1) and the ratios of blossom-end rot fruit were higher than in the Control (Table 3). It is necessary to solve these problems in order to increase the yield of high-quality tomatoes. Moreover, it is necessary to examine a method of exchanging the soil in the lower container during the continuous cropping cultivation. Improvement in the shape of the container is required for this purpose.

\section{REFERENCES}

Azhiri-Sigari, T., Yamauchi, A., Kamoshita, A., Wade, L. J. 2000. Genotypic variation in response of rainfed lowland rice to drought and rewatering. Plant Prod. Sci. 3: 180-188.

Bañoc, D. M., Yamauchi, A., Kamoshita, A., Wade, L. J., Pardales, J. R. 2000. Genotypic variations in response of lateral root development to fluctuating soil moisture in rice. Plant Prod. Sci. 3: $335^{-3} 34$.

Bano, A., Dorffling, K., Bettin, D., Hahn, H. 1993. Abscisic acid and cytokinins as possible root-to-shoot signals in xylem sap of rice plants in drying soil. Funct. Plant Biol. 20: 109115 .

Bolarin, M. C., Estañ, M. T., Caro, M., Romero-Aranda, R., Cuartero, J. 2001. Relationship between tomato fruit growth and fruit osmotic potential under salinity. Plant Sci. 160: $1153^{-1159 .}$

Burgess, S.S.O. 2010. Can hydraulic redistribution put bread on our table? Plant Soil 341: 25-29.

Caldwell, M. M., Dawson, T. E., Richards, J. H. 1998. Hydraulic lift: consequences of water efflux from the roots of plants. Oecologia 113: 151-161.

Cuartero, J., Fernández-Muñoz, R. 1998. Tomato and salinity. 
Sci. Hortic. 78: 83-126.

Davies, W. J., Zhang, J. 1991. Root signals and the regulation of growth and development of plants in drying soil. Annu. Rev. Plant Biol. 42: 55-76.

Dorais, M., Papadopoulos, A., Gosselin, A. 2001. Influence of electric conductivity management on greenhouse tomato yield and fruit quality. Agronomie 21: 367-383.

Gao, Z., Sagi, M., Lips, S. 1998. Carbohydrate metabolism in leaves and assimilate partitioning in fruits of tomato (Lycopersicon esculentum L.) as affected by salinity. Plant Sci. 135: 149-159.

Ho, L. 1999. The physiological basis for improving tomato fruit quality. Acta Hortic. 487: 33-40.

van Ieperen, W. 1996. Effects of different day and night salinity levels on vegetative growth, yield and quality of tomato. J. Hortic. Sci. 71: 99-111.

Johnstone, P., Hartz, T., LeStrange, M., Nunez, J., Miyao, E. 2005. Managing fruit soluble solids with late-season deficit irrigation in drip-irrigated processing tomato production. HortScience 40: 1857-1861.

Kirda, C., Cetin, M., Dasgan, Y., Topcu, S., Kaman, H., Ekici, B., Derici, M., Ozguven, A. 2004. Yield response of greenhouse grown tomato to partial root drying and conventional deficit irrigation. Agric. Water Manage. 69: 191-201.

Liste, H.-H., White, J. C. 2008. Plant hydraulic lift of soil water - implications for crop production and land restoration. Plant Soil 313: 1-17.

Martinez, J.-P., Antunez, A., Pertuze, R., Acosta, M.D.P., Palma, X., Fuentes, L., Ayala, A., Araya, H., Lutts, S. 2012. Effects of saline water on water status, yield and fruit quality of wild (Solanum chilense) and domesticated (Solanum lycopersicum var. Cerasiforme) tomatoes. Exp. Agric. 48: 573-586.
Mitchell, J., Shennan, C., Grattan, S., May, D. 1991. Tomato fruit yields and quality under water deficit and salinity. J. Am. Soc. Hortic. Sci. 116: 215-221.

Ostonen, I., Püttsepp, Ü., Biel, C., Alberton, O., Bakker, M., Lõhmus, K., Majdi, H., Metcalfe, D., Olsthoorn, A., Pronk, A. 2007. Specific root length as an indicator of environmental change. Plant Biosyst. 141: 426-442.

Pulupol, L. U., Behboudian, M. H., Fisher, K. J. 1996. Growth, yield, and postharvest attributes of glasshouse tomatoes produced under deficit irrigation. HortScience 31: 926-929.

Savić, S., Liu, F., Stikić, R., Jacobsen, S. E., Jensen, C. R., Jovanović, Z. 2009. Comparative effects of partial rootzone drying and deficit irrigation on growth and physiology of tomato plants. Arch. Biol. Sci. 61: 801-810.

Savić, S., Stikić, R., Radovic, B. V., Bogicevic, B., Jovanović, Z., Sukalovic, V.H.T. 2008. Comparative effects of regulated deficit irrigation (RDI) and partial root-zone drying (PRD) on growth and cell wall peroxidase activity in tomato fruits. Sci. Hortic. 117: 15-20.

Sekiya, N., Araki, H., Yano, K. 2010. Applying hydraulic lift in an agroecosystem: forage plants with shoots removed supply water to neighboring vegetable crops. Plant Soil 341: 39-50.

Sirigu, A., Mameli, M., Chessa, F., Meloni, S. 2006. Effect of partial root zone drying on growth, yield and fruit quality in greenhouse tomato cultivation. Acta Hortic. 747: 219-226.

Tahi, H., Wahbi, S., Wakrim, R., Aganchich, B., Serraj, R., Centritto, M. 2007. Water relations, photosynthesis, growth and water-use efficiency in tomato plants subjected to partial rootzone drying and regulated deficit irrigation. Plant Biosyst. 141: 265-274.

Zhu, J. K. 2002. Salt and drought stress signal transduction in plants. Annu. Rev. Plant Biol. 53: 247. 